Keywords:Filtration, $R M F$, Rotary Microfilter

Retention: Permanent

\title{
Development of a Laminated Disk for the SpinTek Rotary Microfilter
}

D.T. Herman

May 2011

Savannah River National Laboratory Savannah River Nuclear Solutions, LLC Aiken, SC 29808

Prepared for the U.S. Department of Energy under contract number DE-AC09-08SR22470.

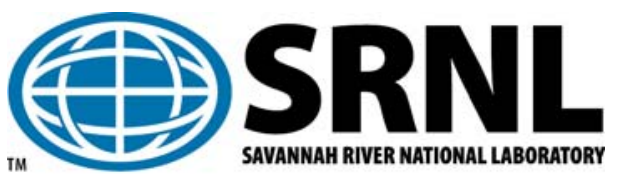


SRNL-STI-2011-00279

Revision 0

\section{DISCLAIMER}

This work was prepared under an agreement with and funded by the U.S. Government. Neither the U.S. Government or its employees, nor any of its contractors, subcontractors or their employees, makes any express or implied:

1. warranty or assumes any legal liability for the accuracy, completeness, or for the use or results of such use of any information, product, or process disclosed; or

2. representation that such use or results of such use would not infringe privately owned rights; or

3. endorsement or recommendation of any specifically identified commercial product, process, or service.

Any views and opinions of authors expressed in this work do not necessarily state or reflect those of the United States Government, or its contractors, or subcontractors.

\section{Printed in the United States of America \\ Prepared for \\ U.S. Department of Energy}




\section{REVIEWS AND APPROVALS}

AUTHOR

D.T. Herman

Date

Advanced Characterization and PR

DESIGN CHECK

C. A. Nash

Date

Advanced Characterization and PR

APPROVAL

F.M. Pennebaker, Manager

Date

Advanced Characterization and PR

S.L. Marra, Manager

Date

Environmental \& Chemical Process Technology Research Programs 


\section{PREFACE OR ACKNOWLEDGEMENTS}

The concept of the laminated disk was developed in partnership with William Greene and Jason Gilmour of SpinTek Filtration. Actual construction and sintering of the disks was performed by Jack Piontkowski of W.S. Tyler Industrial Group. Testing of the disk prototypes was accomplished by Dr. Brian Reed of the University of Maryland. 


\section{EXECUTIVE SUMMARY}

Funded by the Department of Energy Office of Environmental Management, EM-31, the Savannah River National Laboratory (SRNL) partnered with SpinTek Filtration ${ }^{\mathrm{TM}}$ to develop a filter disk that would withstand a reverse pressure or flow during operation of the rotary microfilter. The ability to withstand a reverse pressure and flow eliminates a potential accident scenario that could have resulted in damage to the filter membranes. While the original welded filter disks have been shown to withstand and reverse pressure/flow in the static condition, the filter disk design discussed in this report will allow a reverse pressure/flow while the disks are rotating. In addition, the laminated disk increases the flexibility during filter startup and cleaning operations. The new filter disk developed by SRNL and SpinTek is manufactured with a more open structure significantly reducing internal flow restrictions in the disk. The prototype was tested at the University of Maryland and demonstrated to withstand the reverse pressure due to the centrifugal action of the rotary filter. The tested water flux of the disk was demonstrated to be $1.34 \mathrm{gpm}$ in a single disk test. By comparison, the water flux of the current disk was $0.49 \mathrm{gpm}$ per disk during a 25 disk test. The disk also demonstrated rejection of solids by filtering a $5 \mathrm{wt} \%$ Strontium Carbonate slurry with a filtrate clarity of less the 1.4 Nephelometric Turbidity Units (NTU) throughout the two hour test. 


\section{TABLE OF CONTENTS}



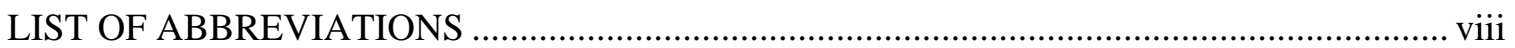

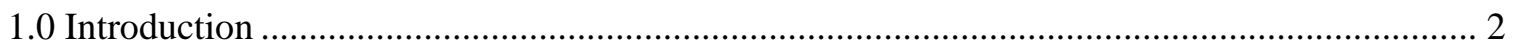

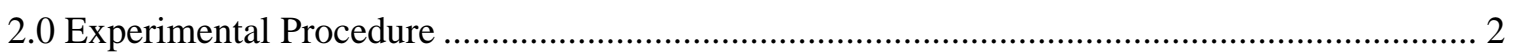

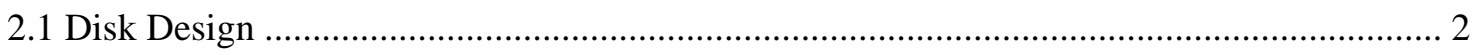

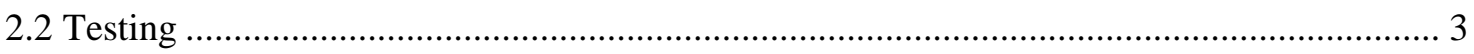

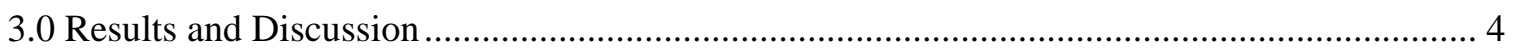

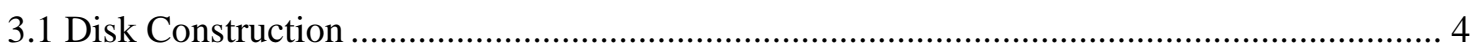

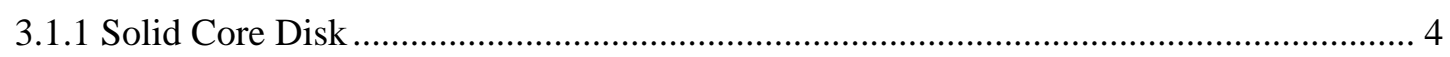

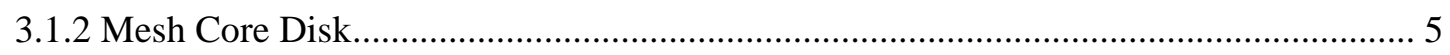

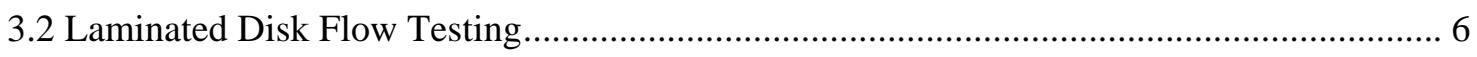

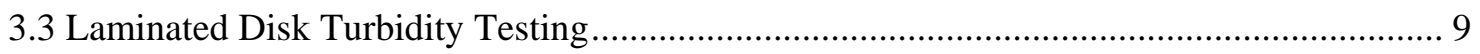

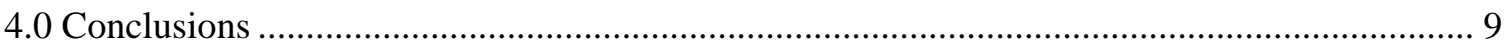

5.0 Recommendations, Path Forward or Future Work ............................................................. 10

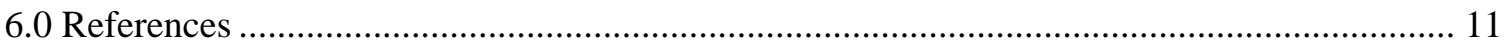

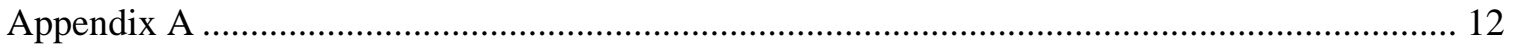




\section{LIST OF FIGURES}

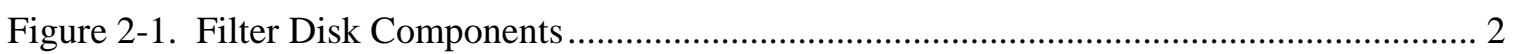

Figure 2-2. Original Edge Welded Filter Disk …..................................................................... 3

Figure 3-1. First Prototype Laminated Disk (Solid Core) with Epoxy Edge ................................ 4

Figure 3-2. Laminated Disk (Mesh Core) with Welded Edge...................................................... 5

Figure 3-3. Laminated Disk (Mesh Core) with Soldered Edge .................................................. 6

Figure 3-4. Permeate Flow versus Pressure Drop for Laminated Disk ........................................ 7

Figure 3-5. Inside Edge View of Welded Disk ...................................................................... 7

Figure 3-6. Inside Edge View of Laminated Disk................................................................. 8

Figure 3-7. Permeate Flow for the Laminated Disk with $5 \mathrm{Wt} \% \mathrm{SrCO}_{3}$ Slurry........................... 8

Figure 3-8. Turbidity Results with a 5 Wt \% Strontium Carbonate Slurry .................................... 9 


\section{LIST OF ABBREVIATIONS}

$\begin{array}{ll}\text { DOE } & \text { Department of Energy } \\ \text { EM } & \text { Environmental Management } \\ \text { NTU } & \text { Nephelometric Turbidity Units } \\ \text { RMF } & \text { Rotary Microfilter } \\ \text { SRNL } & \text { Savannah River National Laboratory }\end{array}$




\subsection{Introduction}

The Savannah River National Laboratory (SRNL) has been working with SpinTek Filtration ${ }^{\mathrm{TM}}$ to adapt the rotary microfilter for radioactive service in the Department of Energy (DOE) Complex. One potential weakness is the loose nature of the membrane on the filter disks. The current disk is constructed by welding the membrane at the outer edge of the disk. The seal for the center of the membrane is accomplished by an o-ring in compression for the assembled stack. The remainder of the membrane is free floating on the disk. This construction requires that a positive pressure be applied to the rotary filter tank to prevent the membrane from rising from the disk structure and potentially contacting the filter turbulence promoter. In addition, one accident scenario is a reverse flow through the filtrate line due to mis-alignment of valves resulting in the membrane rising from the disk structure. The structural integrity of the current disk has been investigated $^{1}$, and shown that the disk can withstand a significant reverse pressure in a static condition. However, the disk will likely incur damage if the filter stack is rotated during a reverse pressure.

The development of a laminated disk would have several significant benefits for the operation of the rotary filter including the prevention of a compromise in filter disk integrity during a reverse flow accident, increasing operational flexibility, and increasing the self cleaning ability of the filter. A laminated disk would allow the filter rotor operation prior to a positive pressure in the filter tank. This would prevent the initial dead-head of the filter and prevent the resulting initial filter cake buildup. The laminated disk would allow rotor operation with cleaning fluid, eliminating the need for a recirculation pump. Additionally, a laminated disk would allow a reverse flow of fluid through the membrane pores removing trapped particles.

\subsection{Experimental Procedure}

\subsection{Disk Design}

The original filter disk was comprised of a solid steel structure plate with a stainless steel mesh on each side and covered with the stainless membranes. A photo of the disk components is shown as Figure 2-1.



Figure 2-1. Filter Disk Components

The original disk was welded at the edge only, allowing the filter membrane to float. A photo of the original edge welded disk is shown as Figure 2-2. 


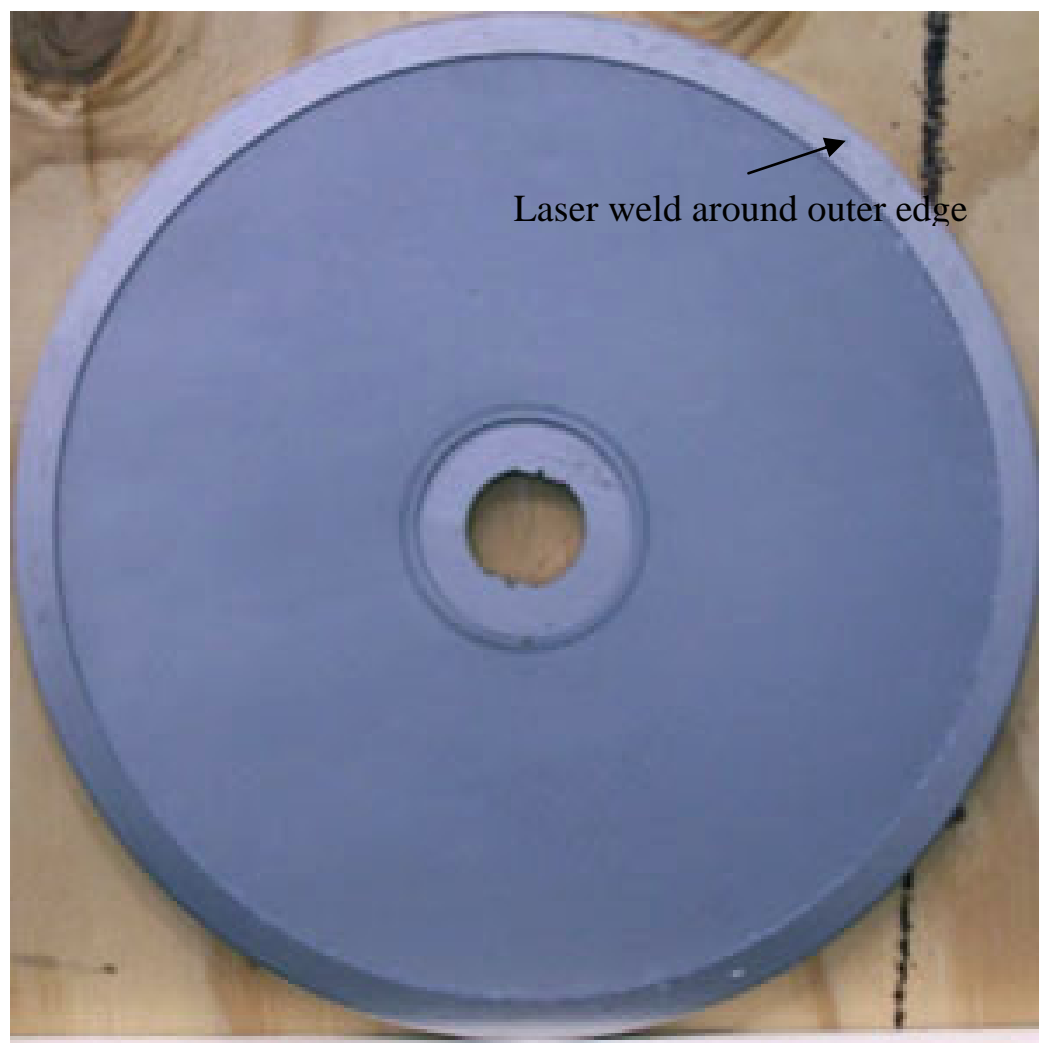

Figure 2-2. Original Edge Welded Filter Disk

The concept for the first prototype sintered disk used the same construction but sintered the components removing the float of the membrane.

The second concept of the SpinTek filter disk is comprised of multiple layers of stainless steel mesh acting as support and drainage layers and the stainless steel filter membranes. The layers of mesh are calendared to insure the maximum contact between layers for the best sinter bonding of the mesh layers. All layers are compressed during the high temperature heat treat process, to diffusion bond the filter media and mesh layers into a filter plate.

The resulting SpinTek filter plate is water jet cut to dimension. After water jet cutting, the edge on the circumference is open and must be sealed for proper operation. This is completed by welding the edge to make the seal. The oxidation from welding is removed with a mild acid, rinsed thoroughly and ultrasonically cleaned and dried prior to packaging and shipment.

\subsection{Testing}

All disks were subject to a reverse pressure test to assure that they would withstand a minimum of 25 psi backpressure. The later prototypes (mesh core) were subjected to a clean water test to determine disk flow performance and a solids rejection test using strontium carbonate. The strontium carbonate test is the same as used in filter acceptance test ${ }^{2}$.

Testing on the prototype disks was performed by Dr. Brian Reed of the University of Maryland. Dr. Reed used a SpinTek single disk rotary filter for testing. The only change to the equipment was the ability to feed a flow to the filtrate line. The test parameters were: 
Feed flow rate of 1.5-2.5gpm

Feed pressure of 8 - 55psi

Pressure difference of 3 to 27psi

Feed temperature of $67+/-5$ Fahrenheit

Rotary Speed of 1200rpm

\subsection{Results and Discussion}

\subsection{Disk Construction}

\subsubsection{Solid Core Disk}

The first prototype disk used the same construction as the current standard welded disk. Specifically, a solid support plate with stainless steel mesh on both sides was covered with Pall 0.5 micron stainless steel membranes. These layers were sintered together to form the disk assembly. For this first prototype, the edge was sealed with a bead of epoxy. A photograph of the completed disk is shown as Figure 3-1.

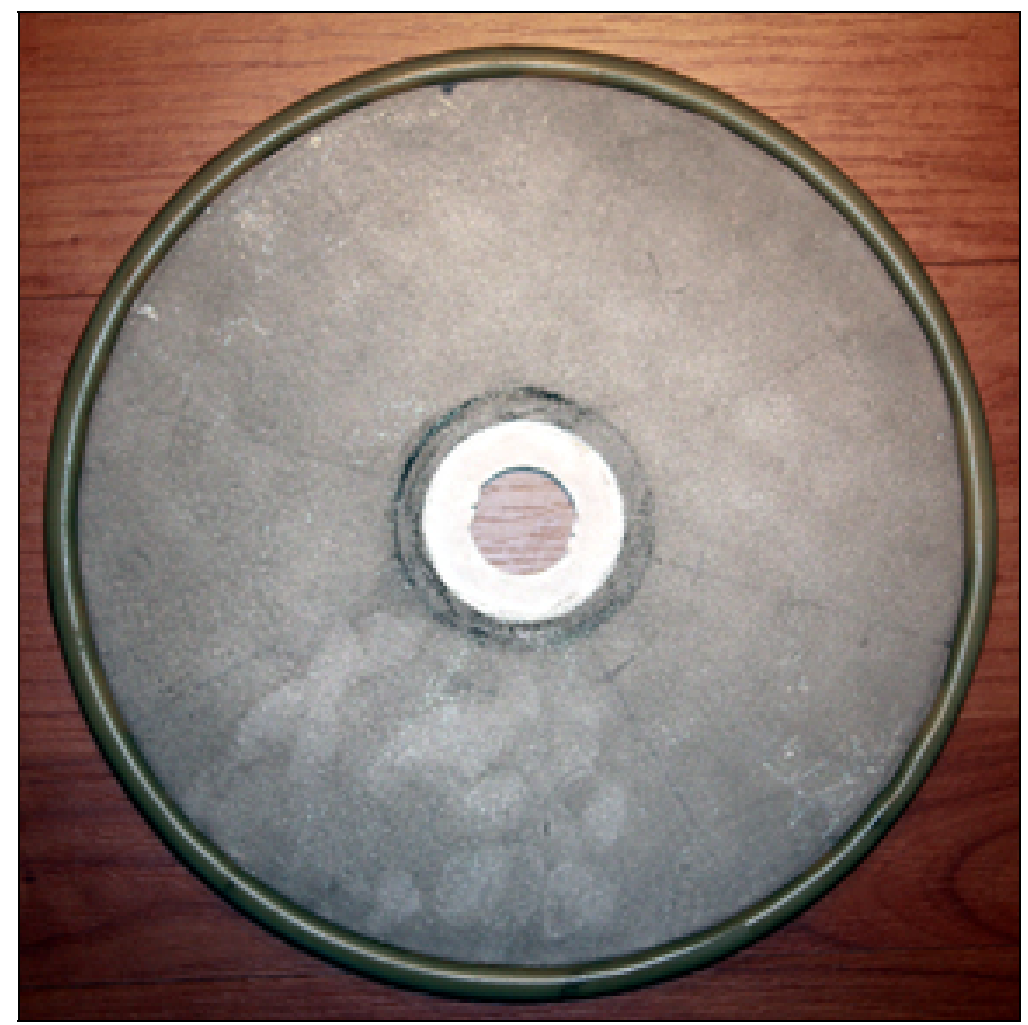

Figure 3-1. First Prototype Laminated Disk (Solid Core) with Epoxy Edge

During the initial sintering, three small holes were accidentally made in the filter membrane. These were sealed with epoxy (not shown in the figure). The intent of this disk was to prove the concept of laminating the disk layers together. A bubble point test was conducted where the disk was submerged in water and compressed air was applied to the inside of the disk. The disk was subjected to a reverse pressure of air starting at 6 psi and increased to a maximum of $60 \mathrm{psi}$. The location and pattern of air bubble formation on the disk surfaces was noted during the test. 
Bubbles were observed across the membrane and not predominately at the outer edge, demonstrating that the epoxy was sufficient to seal the disk. The bubble pattern was relatively even across the disk, though some areas did lack bubble coverage. This indicated that there was a flow restriction in some areas of the disk or plugging of pores potentially due to the sintering process.

\subsubsection{Mesh Core Disk}

Two additional disks were fabricated with a stiff mesh center support. The mesh and filter media were materials used for similar lamination products by the vendor. These disks did not show any flaws in the membrane.

Sealing the edge of the disk proved challenging because of the additional void space and open nature of the mesh. Initial attempts resulted in significant warping of the disk. In addition to welding, the edge was soldered with chemically resistant silver solder. A photo of the disk with the welded edge is shown as Figure 3-2. The disk with the soldered edge is shown in Figure 3-3.

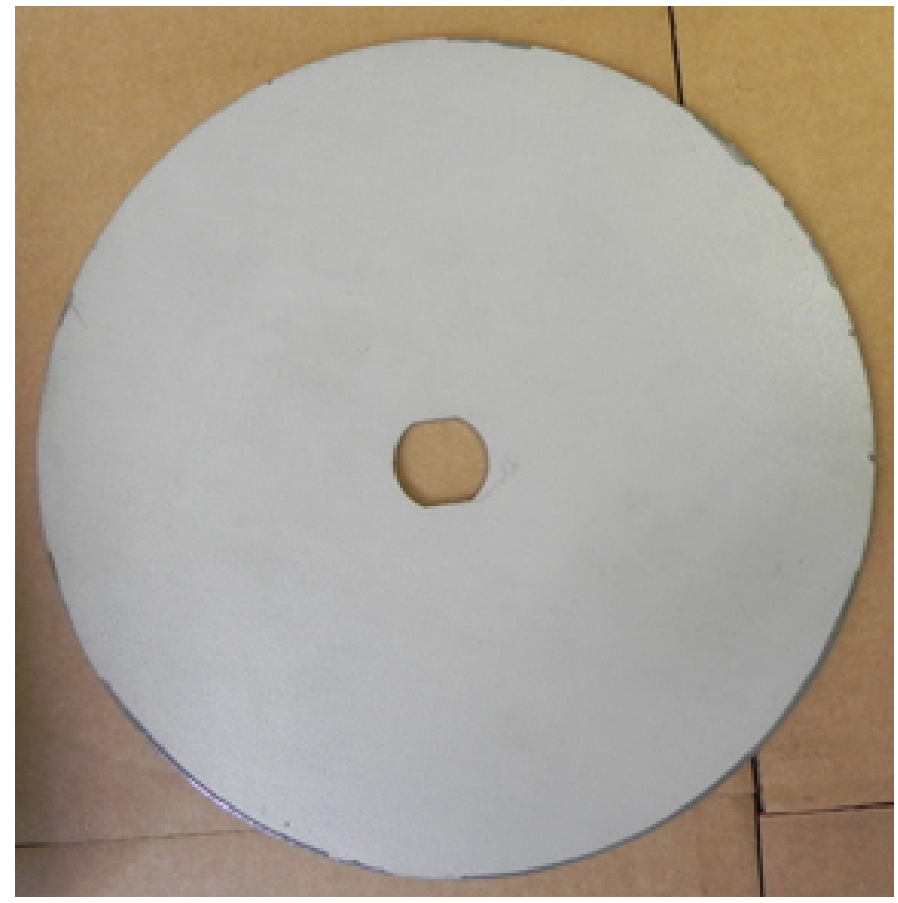

Figure 3-2. Laminated Disk (Mesh Core) with Welded Edge 


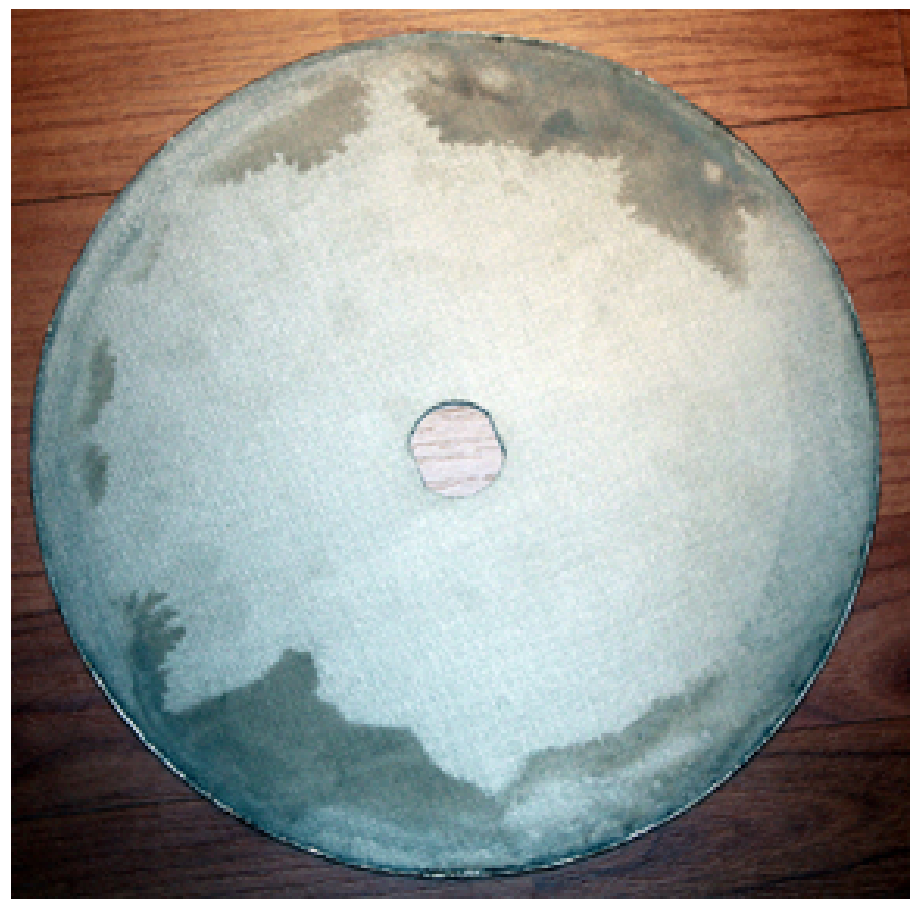

Figure 3-3. Laminated Disk (Mesh Core) with Soldered Edge

The use of the layered mesh instead of the solid steel core also has the benefit of being significantly lighter. The typical weight of the original welded disk is approximately 1250 grams. The weight of the laminated disk is approximately 680 grams, $54 \%$ of the original disk weight. The reduction in weight will reduce the stress on the bearings and mechanical seals of full scale systems, thus potentially increasing component lifetime.

\subsection{Laminated Disk Flow Testing}

The welded disk was tested in a single disk rotary filter. The filter system was modified to allow flow in the filtrate line. Testing was completed over two days in which pressure was applied in the forward and reverse direction each day of testing. The resulting water flow rates are shown in Figure 3-4. The permeate flow rate from the acceptance testing of the 25 disk rotary filter used in the 1000 hour testing is shown in the chart for comparison. Note that the laminated disk achieved the equivalent permeate flow rate as the 25 disk unit acceptance test with only $25 \%$ of the applied differential pressure. 




Figure 3-4. Permeate Flow versus Pressure Drop for Laminated Disk

This dramatic increase in flow for the laminated disk is primarily due to the significant reduction in the internal flow resistance of the disk. The drop in resistance is a result of using the open mesh as the disk support. Figure 3-5 shows a close-up photo of the center of the original disk. All filtrate flow must pass through this circumferential gap which is approximately 0.020 ” thick.

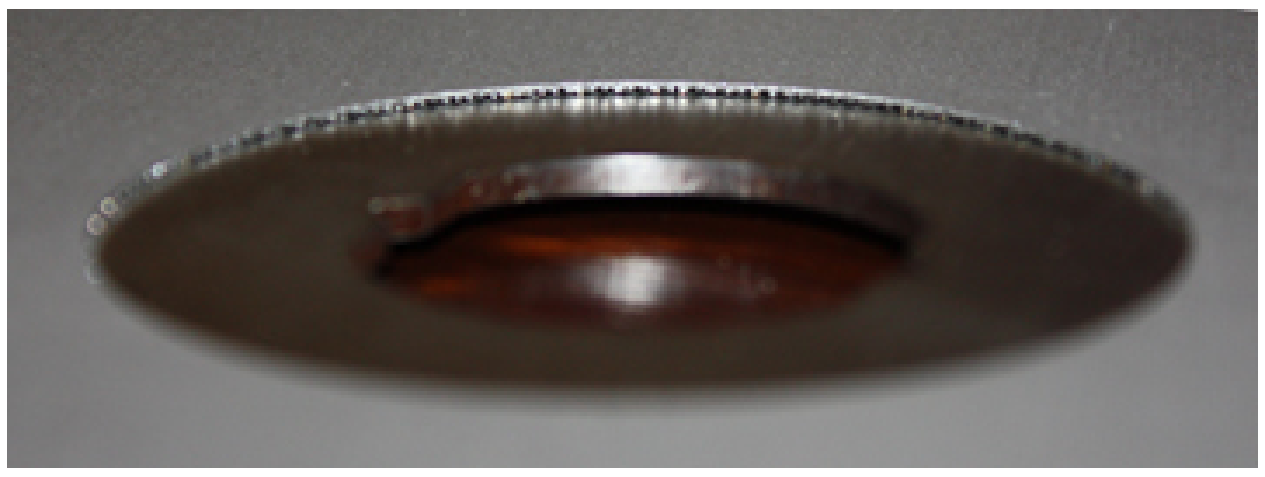

Figure 3-5. Inside Edge View of Welded Disk

This flow area is restricted compared to the open area provided by the mesh structure shown in Figure 3-6. 




Figure 3-6. Inside Edge View of Laminated Disk

The laminated disk also has a larger effective media area. The weld ring on the original filter disk obstructs some media area giving an effective filtration area of $0.98 \mathrm{ft}^{2}$. Since the laminated disk eliminates the weld ring the effective area is increased by approximately $12 \%$ with the same disk dimensions.

The filter integrity was tested using a $5 \mathrm{wt} \%$ strontium carbonate slurry. This is the same slurry used in the 25 disk rotary filter acceptance tests. The result of a three hour filtration test is shown in Figure 3-7.

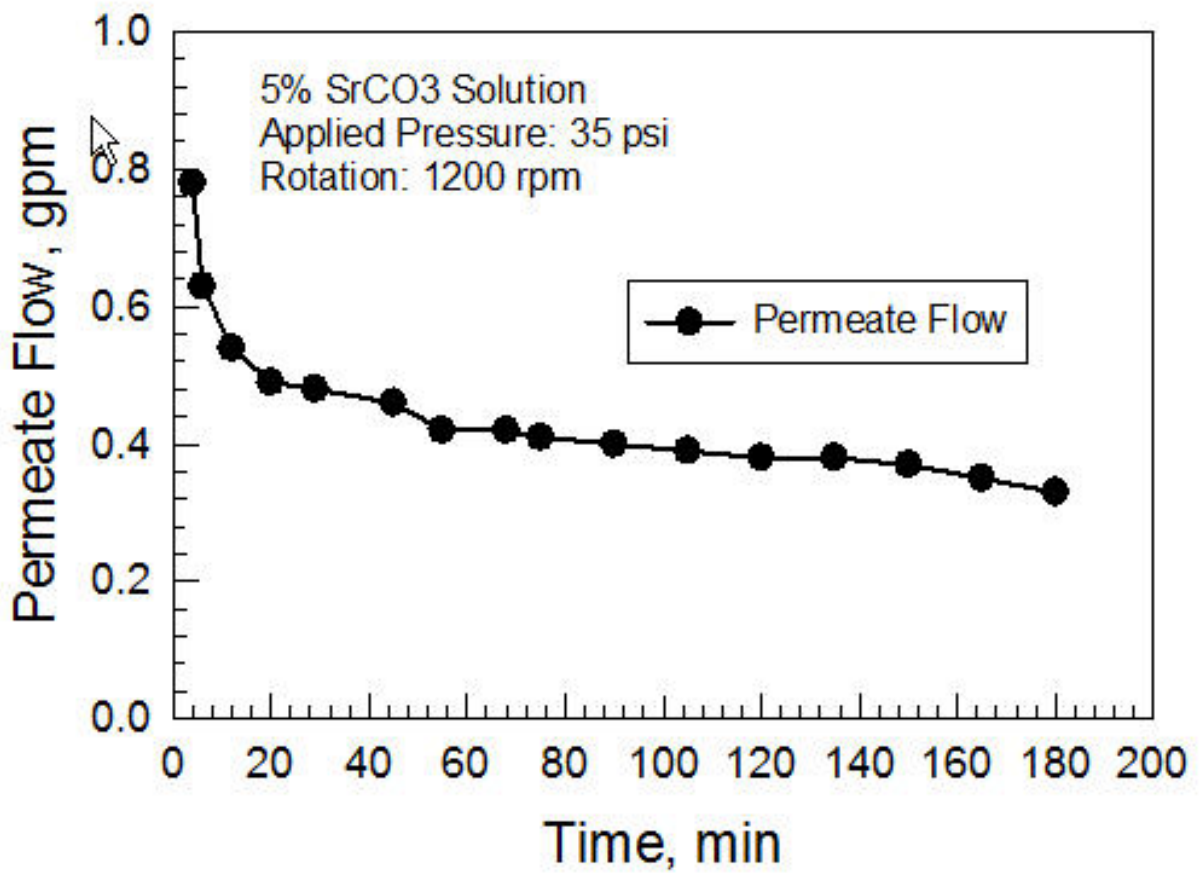

Figure 3-7. Permeate Flow for the Laminated Disk with $5 \mathrm{Wt} \% \mathrm{SrCO}_{3}$ Slurry 


\subsection{Laminated Disk Turbidity Testing}

Turbidity was measured in the filtrate samples obtained during the $\mathrm{SrCO}_{3}$ slurry testing. A graph of the measurements over the three hour test is illustrated as Figure 3-8. The low turbidity values demonstrate that the disk was sufficiently sealed at the edge without delaminating or other adverse effects caused by reverse flow through the rotary membrane. The results of the test are very similar to the tests run on the 25 disk units with normal flow.

It should be noted that the disk was run in a separate test using oily water for a different application. The test parameters will not be discussed here; however, the disks with the sintered membranes did not reject the oil as well as the original welded disks. It is believed that the sintering process affected the pore structure enough to allow the oil to pass. The sintered disks did not show any negative effect during testing with the $\mathrm{SrCO}_{3}$ or simulant slurry.

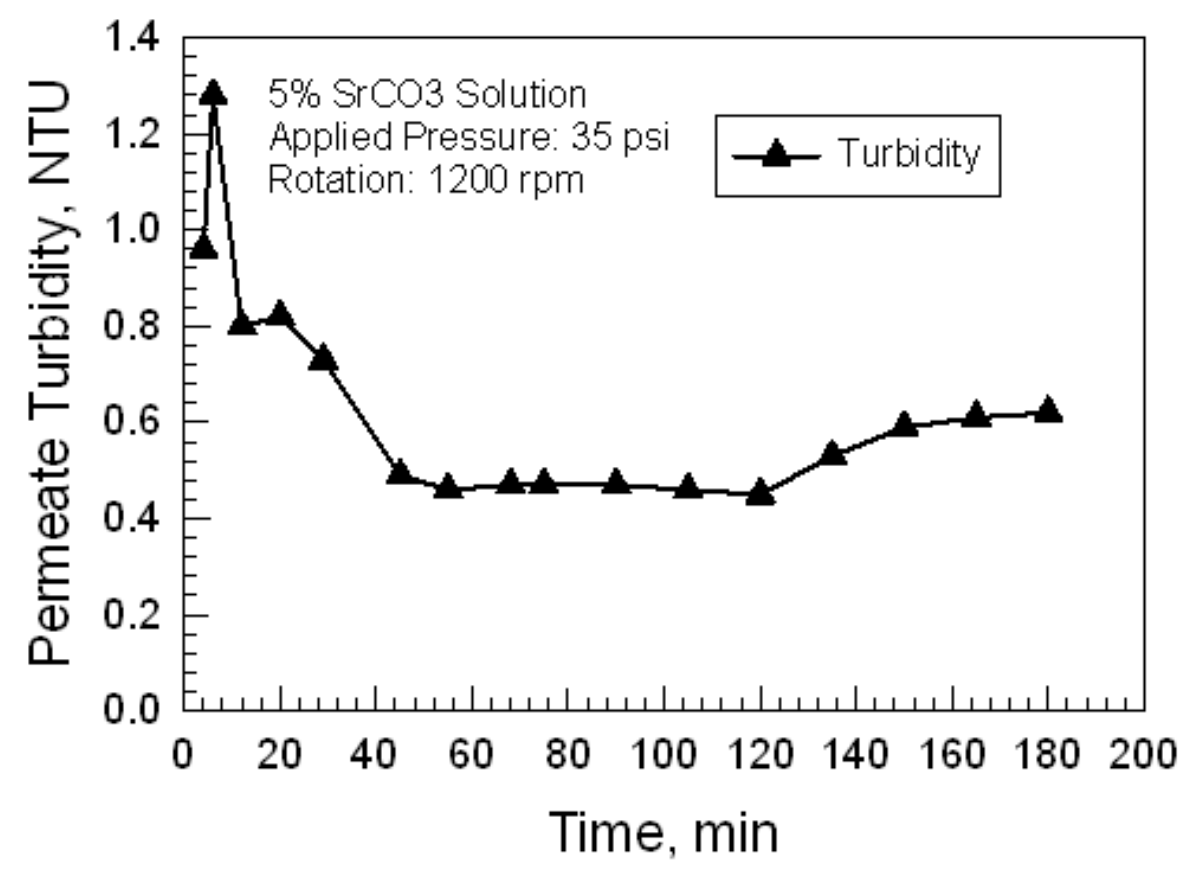

Figure 3-8. Turbidity Results with a 5 Wt \% Strontium Carbonate Slurry

\subsection{Conclusions}

The laminated disk has several potential advantages including startup flexibility, cleaning, and durability. This second configuration discussed in this report, utilizing the laminated screens is the recommended construction for the laminated disk. This recommendation is being made based on the increased water flux and reduction in disk weight.

Laminating the membrane eliminates the need for a positive pressure on the disk to prevent the membrane from lifting off of the surface of the disk. This setup eliminates the concern of the 
membrane contacting the turbulence promoters by either rotating the disks without a positive pressure in the filter tank or during a reverse pressure accident.

The laminated disk allows startup of the rotor prior to establishing the feed flow. This was not possible with the previous disks since the membrane could rise off of the disk substructure and possibly contact the turbulence promoter and compromise the integrity of the membrane. The ability to start the rotor prior to establishing a positive pressure across the membrane allows the rotor to be in operation prior to the start of filtration. This type of start-up will prevent the initial buildup of a filter cake on the membranes. Earlier testing had demonstrated that it is easier to prevent the buildup of filter cake than it is to remove one that is already established. ${ }^{3}$

The ability to operate the rotor without the positive pressure across the membrane applied by a pump simplifies the cleaning process. Without the pressure restriction, the feed tank can be isolated and filled with cleaning solution. The rotor can be operated to provide turbulence to aid in cleaning the disks. This allows a known/fixed quantity of cleaning solution be added to the filter for the cleaning process. The volume of the filter and housing is approximately 11 gallons. The ability of the disks to withstand a reverse flow gives the potential to utilize a surge tank on the filtrate line that could be used to intentionally flow the filtrate back through the disks cleaning the pores of the membrane. Additionally, previous studies have shown that simply rotating the disks without a positive pressure in the process fluid will act to clean the disks and break up the filter cake.

The ability of the laminated disks to withstand a reverse pressure and flow eliminates the concern of an accidental back pressurization. Back pressurizations can be caused by improper valve alignment, faulty check valves, or valve failures. Elimination of potential damage to the membranes by any of these events significantly reduces the consequences of these accident scenarios.

The reduction of weight in the disk by $46 \%$ reduces the load on the filter bearings and mechanical seals. The reduced stress is expected to reduce the wear on these items and potentially extend operational lifetime of the filter system.

\subsection{Recommendations, Path Forward or Future Work}

The first prototypes of the laminated disk have demonstrated the ability to withstand a reverse pressure due to rotation of the filter disks at approximately $1200 \mathrm{rpm}$. Additional testing should be performed to determine the strength of the disk. Similar testing has been performed on the welded disks. ${ }^{1}$

Additionally, additional disks should be fabricated to demonstrate the ability to fabricate production quantity of disks. A full scale test with a stack of 25 disks should be tested to determine disk performance, including a similar endurance test (i.e. $1000 \mathrm{hr}$ test) for the new disks. 
Revision 0

\subsection{References}

${ }^{1}$ M.D. Fowley, D.T. Herman, "Backpressure Testing of Rotary Microfilter Disks,” SRNL-STI-2010-00790, April, 2011.

2 D.T. Herman, “Rotary Filtration System,” M-SPP-A-00110, March 2009.

${ }^{3}$ D.T. Herman, D.B. Stefanko, M.R. Poirier, S.D. Fink, "Testing of a Full-Scale Rotary Microfilter for the Enhanced Process for Radionuclides Removal,” SRNL-STI-2009-00183, January, 2009. 
SRNL-STI-2011-00279

Revision 0

\section{Appendix A}

This will be the SpinTek PDF 
SRNL-STI-2011-00279

Revision 0 


\section{Distribution:}
A. B. Barnes, 999-W
D. A. Crowley, 773-43A
S. D. Fink, 773-A
B. J. Giddings, 786-5A
C. C. Herman, 999-W
S. L. Marra, 773-A
F. M. Pennebaker, 773-42A
W. R. Wilmarth, 773-A
M. D. Fowley, 786-5A
M. R. Poirier, 773-42A
C. A. Nash, 773-42A
P. C. Suggs, 704-S
M. T. Keefer, 766-H
T. H. Huff, 773-66A
M. A. Rios Armstrong, 773-66A
R. E. Edwards, 773-67A
D. M. Patel, 773-66A
P.R. Jackson, 703-46A
K.H. Subramanian, 766-H 